\title{
ESCALA DE IDENTIDADE PROFISSIONAL POLICIAL MILITAR (EIPPM): EVIDÊNCIAS DE VALIDADE FATORIAL E PREDITIVA
}

SCALE OF THE PROFESSIONAL IDENTITY OF MILITARY POLICE (SPIMP): EVIDENCES OF FACTOR AND PREDICTIVE VALIDITY

Recebido em 17.06.2014. Aprovado em 12.05.2015 Avaliado pelo sistema double blind review DOl: http://dx.doi.org/10.12712/rpca.v9i2.462

\section{Thiago Gomes Nascimento}

tgn.1980@gmail.com

Universidade de Brasília, Brasília/DF, BRASIL

Université d'Aix-Marseille, FRANÇA

\section{Cláudio Vaz Torres}

claudio.v.torres@gmail.com

Universidade de Brasília, Brasília/DF, BRASIL

\section{Breno Giovanni Adaid-Castro}

brenoadaid@gmail.com

Universidade de Brasília, Brasília/DF, BRASIL

\begin{abstract}
Resumo
O constructo Identidade Profissional tem sido apontado com útil para a compreensão do comportamento humano no trabalho; contudo falta uma medida confiável da identidade profissional. O presente trabalho buscou desenvolver essa medida, testá-la no âmbito da Polícia Militar do Distrito Federal e validá-la psicometricamente. Entrevistas realizadas com doze policiais, soldados, cabos e sargentos e a alicerce teórico da Teoria da Identidade Social de Tajfel (1982-83), identidade no trabalho e identidade organizacional serviram de base para a elaboração das questões. O questionário foi respondido por 600 indivíduos. Com procedimentos de análise fatorial, com rotação oblíqua, foram finalmente identificadas cinco fatores da identidade profissional percebida. (1) Ambiente institucional e profissional favorável $(\alpha=0,81)$, (2) Relacionamento conflituoso no trabalho $(\alpha=0,70),(3)$ Abertura no trabalho $(\alpha=0,85)$, (4) Vocação policial $(\alpha=0,65)$ e (5) Respeito profissional e social $(\alpha=0,64)$. Uma vez comprovada à adequação dos cinco Fatores descritos, justifica-se considerá-los para compreender os antecedentes da formação da Identidade Profissional do Policial Militar do DF. O cálculo do alfa de Cronbach indicou um índice de confiabilidade adequado para a utilização do instrumento.
\end{abstract}

Palavras-chave: Identidade profissional. Polícia militar. Validação de medidas.

\begin{abstract}
The construct of Professional Identity is being considered by scholars as useful to the understanding of human behavior at work. Yet, up to this stage, there is a lack of a reliable scale of the professional identity of military police. The present study aimed the development of reliable scale of the professional identity of military police, validating it with members of the Military Police. Interviews were conducted with twelve police officers, soldiers, privates and sergeants. The theoretical basis of Tajfel's (1982-83) Social Identity Theory was used to the development of the interview questions. Afterwards, a questionnaire was administered and responded by 600 police officers. Through factor analyses, five factors were identified, which relate to the perceived professional identity. (1) Institutional environment and favorable professional $(\alpha=.81)$; (2) Conflictive work relationship $(\alpha=.70)$; (3) Openness at work $(\alpha=.85)$; (4) Police vocation $(\alpha=.65)$; and (5) Professional and social respect $(\alpha=.64)$. Once proven the suitability of the five factors described, it is justified to consider them to understand the background to the formation of professional identity of the Federal District Military Police. Cronbach's alphas indicate an adequate reliability coefficient for the use of this instrument.
\end{abstract}

Keywords: Professional identity. Military police. Instrument validation. 


\section{Introdução}

Nos últimos 20 anos, as investigações sobre policia têm recebido maior atenção das ciências humanas e sociais no Brasil. Entretanto, este cenário nem sempre foi propício, ao ponto de pesquisadores, como por exemplo, Bayley (2006) apontar que numerosos estudos sobre legislações, cortes, exércitos, gabinetes, partidos políticos, burocracia em geral serem frequentes, mas dificilmente encontrava-se pesquisas sobre polícia. Segundo o mesmo autor, os temas de pesquisa relacionados à Polícia, durante muito tempo, foram investigados somente nos momentos de repressão política e voltados para tais contextos. Pode-se, contudo, salientar que, em virtude dos problemas causados pelo atual aumento da violência e criminalidade, especialmente nas grandes cidades, pode auxiliar na explicação no aumento de investigações sobre as instituições de segurança pública, sobre as mais diversas temáticas.

Os temas relativos aos fenômenos sociais contemporâneos têm sido largamente discutidos sobre diversos enfoques, um ponto de destaque é o que trata esses fenômenos sob a égide da identidade. Desde o início das ponderações no domínio das ciências humanas e sociais contemporâneas a questão da identidade foi abordada por intermédio da noção do si-mesmo (self), idealizada como remetendo a perspectivas coletivas para uns e perspectivas mais pessoais para outros (CERULO, 2007, ELLEMERS; SPEARS; DOOSJE, 2002, STETS; BURKE, 2000), sendo discutida desde o seu ponto de vista individual, ou pessoal, até o aspecto social.

Portanto, parte-se da compreensão que o conceito de self é uma construção mental complexa, fruto de uma relação dialética que considera o indivíduo igual a seus pares, mas único na sua existência, na sua experiência e vivência pessoal. Enquanto tema central na Psicologia Social, esse conceito é de difícil tradução. Etimologicamente, self é traduzido como si mesmo, ou a pessoa que um indivíduo é, e ainda a forma como alguém se comporta. As tentativas de auto-representação dos indivíduos são permeadas pela igualdade e a diferença permeiam a todo o momento as tentativas de auto-representação (MYERS, 2014). Assim, uma identidade bem construída é aquela em que existe o delineamento e se impõe os limites entre a individualidade e os grupos aos quais a pessoa está vinculada. Disso resulta que, mesmo reunidos na presença física, o eu e o grupo se encontram separados nos processos psíquicos (MACHADO, 2003). A identidade se relaciona ainda aos auto-esquemas, ou estruturas cognitivas e afetivas sobre aspectos de si mesmo. Essas estruturas referem-se às concepções claras que as pessoas possuem sobre certos atributos próprios. Mesmo que os indivíduos não possuam esquemas sobre todos os aspectos que os constituam, as situações sociais são eliciadoras importantes sobre os auto-esquemas.

O estudo da identidade constitui, assim, um pilar fundamental no pensamento moderno (CERULO, 1997). Introduzidos pelas obras de Cooley (1902), Cooley (1922) e Mead (1909), Mead (1910) e Mead (1934), os estudos de identidade têm evoluído e crescido de forma central no discurso atual, pois tornam-se importantes para melhorar a compreensão das práticas singulares ou coletivas que permeiam a atualidade, sobretudo em relação às práticas das organizações.

Diante disso, o objetivo do presente trabalho é apresentar evidências de validade, fatorial e preditiva, no contexto brasileiro, de uma medida de identidade profissional do Policial Militar. A estrutura da Teoria da Identidade Social - TIS (Tajfel, 1982-83; Tajfel \& Turner, 1979), bem como as discussões sobre identidade no trabalho e identidade organizacional, mostram-se adequadas para subsidiar as discussões a cerca da identidade profissional do policial militar.

A partir dessa introdução, a seção seguinte abordará a teoria da identidade social, que é uma das mais importantes teorias no conjunto atual dos modelos sobre as relações intergrupais em psicologia social (AMÂNCIO, 1993). Posteriormente, considerações sobre a identidade (social) no trabalho e organizacional são apresentadas. Em seguida, será apresentado o método, resultados e discussões. Por fim, são feitas as conclusões.

\section{Referencial Teórico}

A primeira parte desta seção aprofundará as discussões sobre a Teoria da Identidade Social (2.1). Em segundo lugar, será abordada a identidade social no contexto do trabalho (2.2). Posteriormente a seção reserva espaço para a identidade organizacional (2.3). E, por fim, apresenta-se uma busca em bases de periódicos brasileiros sobre escalas de identidade no contexto policial (2.4). 


\section{Teoria da Identidade Social}

A identidade social é definida como uma representação que um indivíduo dá a si mesmo por pertencer a um grupo (TAJFEL,1981). Complementando essa definição, Brewer (1997) esclarece que a identidade social de um indivíduo é constituída por uma série de identificações sociais que esse indivíduo tem com várias categorias sociais. Ressalta, ainda, esse autor que nem todas as identificações são privilegiadas, ativadas ou salientadas a qualquer momento. Em um dado momento, a identidade social é composta de poucas identificações selecionadas para servir a um contexto social particular.

$\mathrm{Na}$ perspectiva intergrupal da identidade social, a concepção da categorização social é revelada como um instrumento que segmenta, classifica e ordena o ambiente social, servindo também como um sistema de orientação, que ajuda a criar e definir o lugar do indivíduo na sociedade. Assim, os grupos sociais contribuem para a construção da identidade social dos seus membros, sendo, a sociedade responsável, não só pela definição, mas também pela criação da realidade psicológica (TAJFEL, 1983).

A identidade social é, em larga medida, relacional e comparativa. Neste sentido, na acepção de Tajfel (1983) "O reconhecimento da identidade em termos socialmente definidos tem várias consequências ao nível de pertença de grupo" (p.291). Para Tajfel e Turner (1979) a identidade social se relaciona ao conhecimento que o indivíduo tem de que pertence a um grupo, acrescido de significação e valor emocional. Grupo social, para os autores, é definido como dois ou mais indivíduos que compartilham uma identificação social comum (e percebem a si mesmos como pertencendo à mesma categoria social).

A primeira dessas consequências, segundo Tajfel (1983) diz respeito a um indivíduo se manter em um grupo e a buscar novos grupos que contribuam para alguns aspectos da sua identidade que gerem satisfação. Se ao contrário, o grupo não preencher este requisito, o indivíduo tenderá a abandoná-lo, a não ser que seja impossível abandonar esse grupo por razões objetivas ou por colocar em conflito valores importantes, por exemplo, parte da autoimagem aceitável socialmente.

Se o abandono do grupo apresenta as dificuldades referidas, então há pelo menos duas soluções possíveis: 1) mudar a interpretação individual dos atributos do grupo de modo a que as suas características indesejáveis (o estatuto baixo do grupo, por exemplo) se tornem justificáveis, ou aceitáveis por meio de uma reinterpretação; ou 2) aceitar a situação tal como é e empenhar-se na ação social que possa levar às mudanças desejáveis na situação. (Tajfel, 1983).

A última consequência leva em conta que nenhum grupo vive sozinho em determinada sociedade, disso resulta que, ao se realizar a reinterpretação dos atributos e se empenhar na ação social só fará sentido, quando ocorrer à comparação entre outros grupos. A identidade social de uma pessoa é constituída por um grande número de identificações sociais que as pessoas possuem com várias categorias sociais. Porém, nem todas as identificações são privilegiadas, ativadas ou salientes a qualquer momento. A identidade social em um dado momento é composta de poucas identificações selecionadas para servir a um contexto social particular. Logo, a identidade social é um fenômeno fluido e contextual. As mesmas relações interpessoais podem ser percebidas tanto como diferenças, que levam a distintas categorias sociais e individuais, como semelhanças - que unem pessoas numa mesma categoria social. A identidade social é dirigida por dois motivos sociais opostos ao nível individual: a necessidade de inclusão e a necessidade de diferenciação (BREWER, 1997).

As consequências sugeridas por Tajfel (1983), em relação ao reconhecimento da identidade, podem ser compreendidas de forma mais explícita quando lemos os ensinamentos de Brandão (1986). Segundo esse autor, as identidades se apresentam como representações grafadas pelo confronto de um indivíduo com o outro; em virtude desse contato, que obriga a exposição, aos processos que envolvem dominar e ser dominado, a tornar-se mais ou menos livre, a poder ou não edificar por conta própria o seu mundo simbólico e, no seu interior, àqueles que qualificam e identificam a pessoa, o grupo, a minoria, a raça, o povo. Identidades portanto, não são apenas o produto inevitável da oposição por contraste, mas o conhecimento social da diferença.

Retomando o segundo aspecto fundamental da Teoria da Identidade Social, tem-se que na acepção de Tajfel, a identidade social de um indivíduo é atrelada ao conhecimento da sua pertença a certos grupos sociais, além de se levar em consideração o significado emocional e avaliativo que resulta desta pertença (TAJFEL, 1982). Assim, a definição de um indivíduo por si mesmo e a definição dos outros é feita em função do seu lugar num sistema de categorias sociais. Por isso, Tajfel (1983) diz que, "esta perspectiva comparativa 
que estabelece a ligação entre a categorização social e a identidade social” (p. 292). Pode-se concluir, que se um grupo não disponibilizar as condições adequadas para a preservação da identidade social positiva, o indivíduo o abandonará.

O último pilar da TIS trata da comparação social ou grupo social, que se estabelece na medida em que dois ou mais indivíduos que compartilham uma identificação social comum, percebem a si mesmos como pertencendo à mesma categoria social. Embora possam ser bastante diferentes, as comparações sociais entre grupos se baseiam na percepção da legitimidade das relações percebidas entre eles. O que faz retomar o conceito de identidade social, que está ligado à necessidade de se obter uma imagem positiva e diferente do grupo próprio, razão esta, que faz a percepção da ilegitimidade numa relação transcender os limites da semelhança intergrupo no plano das comparações sociais relevantes, buscando, assim, as causas da ilegitimidade. Ou conforme esclarece Tajfel (1983), a percepção da ilegitimidade numa relação intergrupo é social e psicológica, é a alavanca aceitável da ação de mudança social no comportamento intergrupo.

A TIS estipula, ainda, que os indivíduos procuram construir uma identidade social positiva mediante comparações entre o seu grupo e o grupo dos outros, sendo estas comparações baseadas em dimensões associadas a valores sociais dominantes e conduzindo ao favoritismo pelo grupo de pertença; a tendência para favorecer o grupo de pertença relativamente ao grupo dos outros (BREWER, 1979, TAJFEL; TURNER, 1979).

Portanto, conforme encerra Souza (2005) a identidade social se constrói pautada sobre inúmeras outras características estudadas pela psicologia, no plano que se desenvolve entre estabilidade e transformação, transformação, essa, que decorre do fato de que a identificação social é um processo psicológico que pressupõe primordialmente em "sentir-se identificado" (p.132) - o que pode ser considerado bastante variável de um contexto para outro.

Tudo o que foi dito serve para coroar os apontamentos de Hughes (citado por CUNHA, 2004, p. 201), onde relata que na fabricação de um profissional não estariam apenas inclusas a totalidade de disciplinas aprendidas em seu processo de formação, mas implicaria, sobretudo, no que chama de "uma espécie de iniciação ao novo papel profissional e numa conversão à nova visão de mundo que permitirá o desempenho desse papel". No transcurso deste processo se verifica uma verdadeira conversão identitária, que consiste em modificar a si mesmo a partir da inclusão de novas ideias sobre a natureza do trabalho a ser realizado, e da aquisição de competências específicas que possibilitem o seu desempenho em termos de uma carreira profissional. Neste processo, tem-se então, a fabricação em si mesmo e no olhar do outro, de uma nova identidade, uma identidade profissional. E que segundo Cunha (2004) essa espécie de infiltração cultural seria condição essencial para a construção dessa nova identidade, considerada a base mesmo de todo processo de socialização profissional. O que pode ser também confirmado nos dizeres de Machado (2003) para quem a identidade constitui, ainda, um fenômeno que se processa durante a vida do indivíduo, atuando como mecanismo regulador dos intercâmbios sociais e da presença do outro na vida pessoal.

\section{Identidade Profissional no Trabalho}

Ao desempenhar papéis (GOFFMAN, 1959, 2011), ou melhor, pelo seu exercício é que os indivíduos constroem ativamente suas identidades (BAUGNET, 1998). Neste sentido, os papéis vinculados ao mundo do trabalho combinam uma faceta da estrutura identitária dos indivíduos e, de acordo com Sainsanlieu (1995), a organização, apresenta-se como um lugar importante para a socialização dos indivíduos que nela trabalham. A organização para Sainsanlieu (1995) apresenta-se como uma instituição de socialização secundária, a qual, depois da escola e da família, modela atitudes, comportamentos a ponto de produzir uma identidade profissional e social.

A noção de identidade profissional é um tanto confusa na literatura, como já foi apontado por Dubar (2005). Para esse autor, a identidade profissional não serve como categorização dos indivíduos em função de suas atividades no trabalho, tampouco às denominações que servem, em um momento específico, para se designar a si mesmas a partir de seu emprego. A identidade profissional, para Dubar (2005), refere-se as formas identitárias definidas a partir de uma configuração eunós vinculadas ao campo das atividades de trabalho remunerado. A identidade profissional básica leva em consideração não somente uma identidade no trabalho, mas também uma projeção do si no futuro, a antecipação de um caminho de emprego e a preparação de uma lógica de aprendizagem, ou melhor, de formação (DUBAR, 2005). 
A visão de identidade profissional de Dubar (2005) é próxima a noção de identidade no trabalho de Sainsanlieu (1977), que designa modelos culturais ou lógicas de atores em organização, restando a distinção entre as duas acepções da identidade em um importante aspecto. As formas visadas não são relacionais, ou seja, as identidades dos atores em um sistema de ação, são também biográficas, que se referem as trajetórias do indivíduo no transcurso de sua vida no trabalho. De acordo com Dubar (1994), as identidades profissionais são formas reconhecidas socialmente, em que os indivíduos se identificam uns com os outros no espaço do trabalho e do emprego. A identidade no trabalho pode ser entendida como a expressão das percepções do indivíduo sobre o significado do seu trabalho.

$\mathrm{Na}$ visão de Machado (2003), existe a força dos processos de categorização na organização, que colaboram para maior consolidação da identidade no trabalho, resultando em sentimentos de vinculação e diferenciação, que favorecem uma visão simbólica do indivíduo como integrante de um espaço imaginário maior na organização. Nesse ambiente, concomitantemente, ocorre um fenômeno responsável pela ligação psíquica do indivíduo à organização, ou seja, a identidade organizacional.

\section{Identidade Organizacional}

O campo de investigação da identidade organizacional apresenta-se como um dos importante para o comportamento humano nas organizações (CORLEY; COLS., 2006) e também uma questão-chave para os gestores (CHENEY, 1991). Desde o trabalho seminal de Albert e Whetten (1985) o interesse em identidade no nível da organização tem sido acompanhado por um vigoroso foco no coletivo, em particular, nos eus organizacionais e suas implicações para a teoria e a prática (HE; BROWN, 2013). O reconhecimento atual $\mathrm{da}$ identidade organizacional torna-se fundamental para o entendimento de questões que levam em consideração a mudança estratégica (RAVASI; PHILLIPS, 2011), a tomada de decisão (RIANTOPUTRA, 2010), os conflitos internos (HUMPHREYS; BROWN, 2002 ), dentre outras.

Outros apontam para a utilidade do conceito de identidade para os níveis de pontes de análise, ligação estruturas e processos de nível micro e nível macro, e, assim, coerentes fios de outra forma díspares de pesquisa baseada em organização (ASHFORTH;
MAEL, 1996; POLZER, 2000). Em última análise, existe um consenso emergente de que "porque a identidade é problemática e ao mesmo tempo tão crítica... que a dinâmica da identidade precisa ser melhor compreendida" (ALBERT; ASHFORTH; DUT'TON, 2000, p. 14).

A identidade organizacional abrange o processo, atividade e acontecimento em que a organização se torna presente na mente de seus integrantes (SCOT'T; LANE, 2000). Compreendendo as crenças compartilhadas pelos sujeitos da organização sobre o que é fundamental, o que a distingue e é duradouro na organização (WHETTEN; GODFREY, 1998), sua constituição é realizada todos os dias, quando o indivíduo vai internalizando a crença de que a organização de pertença é a mesma que era no passado, simbolizando a sua existência temporal (MACHADO, 2003).

Assim, percebe-se que os processos de categorização no ambiente da organização exercem forte influência e contribuem para concretizar a identidade no trabalho, reconhecendo que tais processos derivam em sentimentos de vinculação e diferenciação, que estimulam uma visão simbólica do indivíduo como integrante de um espaço imaginário maior na organização, conforme observado por Tajfel (1983). Disso, surge a identidade organizacional, fenômeno que une o indivíduo à organização.

\section{Escala de Identidade Profissional no Contexto Policial}

Além da utilidade prática de uma medida de identidade profissional, também há implicações relativas à originalidade desse estudo no país. Com o fim de verificar artigos sobre identidade profissional de policias, realizou-se uma busca nos Periódicos Eletrônicos de Psicologia (PePSIC) e no Scientific Electronic Library Online (SciELO Brazil), entretanto não foram encontrados instrumentos disponíveis. Mesmo que nestes sítios se possam encontrar vários artigos que estudaram esta instituição, como pesquisa sobre o serviço oferecido pela polícia militar (FAIAD; DELABRIDA; NASCIMENTO, 2011), atitudes frente à polícia (NASCIMENTO; TORRES; PIMENTEL, 2011), ingresso na carreira policial (MEMANDRO; SOUZA, 1996), violência sofrida por policiais (CAVASSANI,1998, ROSA; BRITO; OLIVEIRA, 2007), representações sociais de policiais (BRITO; SOUZA, 2004), construção do sujeito 
militar (ROSA; BRITO, 2010), relações de poder e gênero (CAPPELLE; MELO, 2010) ou mesmo identidade (MUNIZ, 2001), parece que tal construto não foi estudado em uma perspectiva psicométrica. Não se verificou nenhum relato de pesquisa sobre uma escala para medir identidade profissional de policiais em nossa realidade. Foram, entretanto encontrados dissertações (PINTO, 2000, SOUSA, 2001) e tese de doutorado (SOUSA, 2009), cujo escopo tratou da identidade de policiais militares.

O conhecimento da identidade profissional de policiais pode ser muito útil para a sociedade e para a própria instituição policial. Através deste conhecimento se pode verificar como determinados grupos avaliam esta instituição. Neste sentido, o conhecimento de tais avaliações pode ser um feedback importante do comportamento da Polícia, o que pode ajudar a reforçar comportamentos ou mesmo redefini-los, tendo em vista uma melhor atuação para e com a sociedade.

\section{Método}

\section{Procedimentos}

O presente estudo foi dividido em duas fases distintas, mas complementares, que abordaram diferentes metodologias, a primeira parte aborda a etapa qualitativa e a segunda a etapa quantitativa da pesquisa. O modelo de elaboração de instrumentos psicológicos adotado é baseado em três grandes polos, procedimentos teóricos (fase qualitativa), procedimentos empíricos (experimentais) e procedimentos analíticos (ambos da fase quantitativa) (PASQUALI, 2010).

\section{Fase qualitativa}

Os procedimentos teóricos envolvem a definição das propriedades do sistema psicológico (componentes psicológicos: variáveis de processo e atributos da identidade policial), a definição da estrutura semântica dos componentes (dimensionalidade do atributo), as definições constitutivas e operacionais das variáveis (construção de itens) e a análise teórica dos itens do instrumento (análise semântica e análise de juízes).

A forma como foram realizados estes procedimentos envolveu a utilização de referências bibliográficas, acerca da Teoria da Identidade Social, identidade no trabalho (profissional), identidade organizacional; fontes documentais (regulamentos, portarias, decretos sobre a polícia militar) e empíricas, com a realização de doze entrevistas semiestruturadas realizadas junto a policiais militares de diversos quartéis de Brasília.

Participaram do estudo como entrevistados uma amostra de doze policias de algumas unidades da polícia militar; foram entrevistados um cabo e um soldado, do Batalhão de Operações Especiais (BOPE), do Batalhão de Trânsito (BPTRAN), da Décima Primeira Companhia de Polícia Militar Independente (11 $\left.{ }^{\mathrm{a}} \mathrm{CPMind}\right)$ e do Primeiro Batalhão de Polícia Militar ( $\left.1^{\circ} \mathrm{BPM}\right)$; ademais foram entrevistados um sargento e um soldado, do Terceiro Batalhão de Polícia Militar ( $\left.3^{\circ} \mathrm{BPM}\right)$ e do Quinto Batalhão de Polícia Militar (5 $\left.5^{\circ} \mathrm{BPM}\right)$, totalizando doze entrevistas, Conforme Tabela 1.

Tabela 1 - Dados sociodemográficos dos entrevistados.

\begin{tabular}{cc|cc}
\hline Variáveis & Níveis & Frequência & $\mathbf{0}$ \\
Sexo & Masculino & 11 & 91,7 \\
& Feminino & 1 & 8,3 \\
& & & \\
Graduações & Soldado & 6 & 50 \\
& Cabo & 4 & 33,33 \\
& Sargento & 2 & 16,67 \\
\hline
\end{tabular}

Fonte. Elaborado pelos autores, a partir dos dados da pesquisa.

A entrevista tem como objetivo principal a obtenção de informações do entrevistado, sobre determinado assunto ou problema. No caso específico da presente pesquisa, ela também serviu para o levantamento dos temas que, depois, foram transformados em itens. As entrevistas, que duraram em média uma hora e meia, foram conduzidas por dois pesquisadores de campo treinados para esta finalidade. O procedimento consistiu em buscar policiais de diferentes Unidades Policiais Militares (UPM`s), divididos entre os que apresentam capacitação diferenciada para realizar atividades específicas, como é o caso do BOPE, BPTRAN e do $5^{\circ} \mathrm{BPM}$ e os policiais de unidades que não realizam serviços específicos não têm capacitação diferenciada, ou seja, que desempenhas o policiamento normal, caso do $1^{\circ} \mathrm{BPM}$, do $3^{\circ} \mathrm{BPM}$ e da $11^{\text {a }}$ CPMind. A análise das entrevistas buscou exprimir a interpretação feita pelos policias quanto ao que seja identidade e o seu processo de construção. 
Essas entrevistas foram registradas por escrito ou então gravadas, dependendo da autorização dos policiais, posteriormente foram categorizadas e transformadas em atributos para a construção itens da escala identidade profissional. A forma definida para se analisar o discurso dos policiais entrevistados seguiu o proposto por Gill (2007), em que devemos pensar a análise do discurso dividida em quatro temas principais, "o discurso em si; a linguagem como criadora; o discurso como ação e a organização retórica do discurso". (p.247). Reafirmado pelo conceito de interdiscurso de Maingueneau (2008), no qual apresenta o interdiscurso como predecessor do discurso, não havendo constituição de um sem o outro, sendo nessa relação interdiscursiva que se estrutura a identidade. Desta etapa, qualitativa da pesquisa, resultou a construção da estrutura interna da Escala de Identidade Profissional Policial Militar - EIPPM.

A verbalização dos policiais foi registrada, atentando os entrevistados para realizar perguntas de diversas formas, já que estamos interessados em como os policiais formam sua auto-identidade, mesmo que as perguntas não se encontrem no roteiro pré-definido cabe ao entrevistador não se prender as perguntas sociocientíficas tradicionais (GILL, 2007). Outra etapa da análise do discurso foi realizada a transcrição dos discursos previamente gravados, sendo este procedimento realizado de forma mais detalhada o possível, anotando-se todos os realces, hesitações, pausas, falas repetidas, entonação e respiração produzidas pelos respondentes. Esse recurso é essencial para não se perderem as características da fala.

Neste ponto o pesquisador deve se despir de seus pressupostos e avaliar a maneira de como dá sentido às coisas, já que a experiência de análise do discurso muda a maneira de se experimentar a linguagem e as relações sociais (GILL, 2007). As transcrições foram lidas, relidas, procedimento necessário para a codificação das categorias, determinadas pelas questões de interesse, que foram, assim, separadas e organizadas pela similaridade das respostas.

A busca pelo padrão nos dados tem o objetivo de se verificar a forma da variabilidade, diferença entre os discursos, bem como sua consistência. Nossa preocupação agora muda para a função, na busca de hipóteses ou pressuposições sobre as funções de características específicas do discurso, testando-as frente aos dados (POTTER; WETHERELL, 1987).
Ao se analisar a forma como a linguagem é empregada não pode ser o único ponto a ser examinado pelo pesquisador, este deve estar atento aos silêncios, ou seja, àquilo que não é dito, exigindo-se o entendimento do contexto social, político e cultural em que os textos estão inseridos (GILL, 2007).

Após essa fase as respostas foram da categorizadas em atributos da identidade, procedimento de caráter constitutivo que faz mostra a interação semântica entre os discursos, fazendo com que eles sejam tratados como um processo de tradução. (MAINGUENEAU, 2008). Os atributos revelados pelos policiais foram, então, reunidos aos atributos levantados na literatura, constituindo-se, assim, os 461 atributos da identidade identificados, que foram organizados, pelas respectivas frequências de incidência e agrupados em quatro dimensões da identidade profissional: escolha profissional, instituição: projeto profissional, cultura organizacional e ser policial.

Foi, então, realizada a checagem de itens repetidos, ou que se aproximassem em seu conteúdo, bem como a análise do construto, com o intuito de se verificar a representação comportamental do atributo latente. Esse procedimento foi realizado por especialistas no assunto (dois professores de pós-graduação e 4 estudantes de doutorado em psicologia), com objetivo principal da análise é verificar se os itens apresentam o traço em questão, ou seja, a identidade profissional.

Para cada juiz foi entregue uma tabela contendo os fatores e a definição dos construtos, específicos para a criação dos itens, além dos itens propriamente ditos. A avaliação dos itens que medem os dois fatores de raciocínio verbal, compreensão verbal e fluência verbal, foi realizada levando-se em conta uma concordância de aplicação aos fatores de cerca de 80\% (PASQUALI, 2010), descartando-se os itens que não atingissem tal concordância. Esse procedimento resultou em 73 atributos da identidade profissional do policial militar, transformados em itens, que passaram a compor uma escala Likert, variando de 1: discordo plenamente a 5: concordo plenamente.

Os mecanismos para a construção dos itens respeitou as regras propostas por Pasquali (2010), onde se observou o critério para cada item individualmente e para o conjunto dos itens que medem o construto.

A análise de validação semântica dos itens do instrumento foi realizada por oito policiais militares de diferentes postos e graduações, três soldados, um cabo, um sargento, dois tenentes e um capitão, com o 
objetivo se verificar a compreensão do instrumento, por parte de todo o público alvo da pesquisa. Conforme proposto por Pasquali (2010) esses policiais foram divididos em dois estratos de quatro pessoas, sendo um dos grupos compostos pelos sujeitos constituídos do estrato baixo da população meta, que apresenta menor nível de habilidade. Assim, se o grupo de estrato inferior compreender os enunciados dos itens da escala, espera-se que o estrato com maior habilidade também entenderá.

A este grupo, de oito policiais, foi apresentado cada um dos 73 itens individualmente, solicitando que cada sujeito do grupo reproduzisse cada item, se não ocorresse nenhuma dúvida, o item era compreendido. As poucas divergências apresentadas foram discutidas, onde o pesquisador apontou o que queria dizer com o item, sendo ao final reescrito para uma melhor compreensão. Dois dos itens se apresentavam muito próximos, essa identificação foi relatada pelos dois estratos utilizados para a validação semântica, o que resultou na supressão do item, ficando o instrumento ao final com 72 itens.

Tais procedimentos garantiram, assim, um levantamento exploratório de informações sobre o fenômeno investigado, que garantiu a construção preliminar do instrumento, de forma a atender o que preceitua a literatura.

\section{Fase quantitativa}

Após a conclusão da construção do instrumento, partiu-se para os procedimentos empíricos, que envolveram o planejamento da aplicação do instrumento $\mathrm{e}$ a fase quantitativa de coleta de dados, realizada por meio de sua coleta definitiva. A aplicação dos questionários foi realizada com uma amostra diferente da utilizada no procedimento de validação semântica. Os questionários contendo os 72 itens em uma escala Likert e, ainda, 11 questões demográficas, foram aplicados nas diversas Unidades Policiais Militares e durante a realização de cursos dentro da polícia. Os responsáveis pela coleta liam as instruções constantes no instrumento e explicavam de forma sucinta a forma de se preencher o questionário. Cabe salientar que a PMDF, no momento da coleta, contava com um efetivo de 17.736 policiais na ativa, o que representa a população da pesquisa. Dos 800 questionários encaminhados para os policiais, foram obtidos 600 respondidos e válidos, totalizando uma taxa de resposta de $75 \%$, já após o descarte dos que não foram preenchidos corretamente e os que não retornaram, considerado um tamanho de amostra confiável conforme nos esclarece Field (2009), e Tabachnick e Fidell (2001).

Após ler as instruções o respondente deveria assinalar o ponto na escala que melhor representa sua percepção sobre a identidade profissional. O Termo de Consentimento Livre e Esclarecido (TCLE) fazia parte da primeira folha e ao final se encontrava o questionário sócio-demográfico. Tais dados foram obtidos em salas de aula dos diversos cursos da PMDF e nas diversas unidades policiais.

\section{Amostra}

Tratou-se de uma amostra de conveniência (nãoprobalística) composta por 600 Policiais Militares, provenientes da Polícia Militar do Distrito Federal. Os participantes eram dos diversos graus hierárquicos, Soldados (51,3\%), Cabos (12,2\%), Sargentos $(17,7 \%)$, Subtenente $(0,7 \%)$, Cadete $(9,0 \%)$, Tenente $(3,5 \%)$, Capitão $(4,7 \%)$ e Major (0,5\%). A idade destes variou de 18 a 53 anos $(\mathrm{M}=38,1$; $\mathrm{DP}=7,20)$, com a maioria formada por Policiais de 36 a 44 anos (47,3\%). Predominaram aqueles do sexo masculino (94,0\%), casados $(65,8 \%)$ e que em sua maioria tem três dependentes $(24,5 \%, \mathrm{M}=3,51, \mathrm{DP}=1,59)$. Em sua maioria possuem o ensino médio $(48,7 \%)$ e superior $(43,3 \%)$. A maior parte, dos Policiais participantes, apresenta entre 17 e 24 anos de serviço na PM (44,3\%, $\mathrm{M}=16, \mathrm{DP}=7,38$ ).

\section{Análise dos Dados}

Como parte dos procedimentos analíticos, o SPSS (Statistical Package for the Social Sciences, versão 15) foi utilizado para tabular e realizar as análises dos dados. A busca pelas evidências de validação da estrutura interna do instrumento foi realizada por meio de análise fatorial exploratória, as análises dos itens foram feitas para cada fator individualmente, já que tais análises supõem a unidimensionalidade da aptidão envolvida. Estas análises foram feitas por meio das Técnicas da Psicometria Tradicional (TCT).

Empregaram-se estatísticas descritivas (medidas de tendência central e dispersão, distribuição de frequência), principalmente para caracterizar a amostra. O KMO foi empregado com o objetivo de se conhecer a possibilidade de fatoração do conjunto de itens da EIPPM. A análise de componentes 
principais (CP) foi empregada com o intuito de conhecer a estrutura fatorial da escala. $\mathrm{O}$ alfa de Cronbach foi também calculado para conhecer a consistência interna (precisão) da estrutura fatorial resultante, demandando-se que este seja de ao menos 0,60 para que o instrumento possa ser considerado como psicometricamente adequado em pesquisas exploratórias (HAIR; BLACK; ANDERSON; TATHAM, 2009, PASQUALI, 2010). Finalmente, as análises das relações entre os fatores identificados e as variáveis de registro foram investigadas a partir das regressões múltiplas, com o objetivo de se conhecer evidências de validade preditiva da EIPPM.

\section{Resultados e Discussões}

Nesta etapa, buscam-se cumprir os requisitos dos objetivos do presente estudo, quais sejam, construção e buscar as evidências de validação de uma escala de mensuração da Identidade Profissional do Policial Militar do Distrito Federal, bem como evidências de sua validade preditiva. Após a apresentação, os resultados são discutidos retomando o referencial teórico acerca da identidade profissional.

\section{Análise Fatorial Exploratória}

Os resultados das análises descritivas serão apresentados sob o ângulo de:

a) Análise dos itens: tabela da análise da TCT e análise fatorial, contendo índices de:

Discriminação e Dificuldade

b) Validade do teste

$>\quad$ dados da análise fatorial

c) Precisão do teste

$>\quad$ alfa de Cronbach

$>\quad$ lambda de Guttman

Conforme já mencionado, foi utilizada a análise fatorial exploratória para se buscar evidências de validação da estrutura interna do instrumento. A justificativa para se empregar este procedimento está na possibilidade de se identificar os preditores da identidade profissional do policial militar, que o instrumento mensura e reduzir os dados para facilitar análises posteriores envolvendo as dimensões medidas (PASQUALI, 2009).

Numa análise preliminar dos Componentes Principais
(PC), verificou-se que, a matriz das intercorrelações era fatorizável, isto é, apresentava suficiente covariância que permitisse a procura de fatores. $\mathrm{O}$ coeficiente $\mathrm{KMO}$, que indica tal evento, foi de 0,84 que pode ser considerado bom. Para se decidir o número de fatores a serem extraídos da matriz, a análise forneceu dois dados relevantes: 1) a análise paralela indicou a presença de até dez componentes; e 2) o "scree plot" indicou que a EIPPM apresenta cinco componentes, embora não descarte a possibilidade de até dez componentes. Assim, foram extraídos dez fatores pela análise fatorial (método PAF). Contudo, 28 dos 72 itens não obtiveram carga de, pelo menos, 0,30 . Como consequência, foram eliminados esses 28 itens e novamente foi realizada a análise de PC para os 44 itens restantes.

Essa análise mostrou que, a matriz das intercorrelações era fatorizável, isto é, apresentava suficiente covariância que permitisse a procura de fatores. $\mathrm{O}$ coeficiente $\mathrm{KMO}$, que indica tal evento, foi de 0,844 que pode ser considerado bom. Para se decidir o número de fatores a serem extraídos da matriz, a análise deu, novamente, duas informações relevantes: 1) a análise paralela indicou a presença de até nove componentes (Tabela 2) e o "scree plot" (veja Figura 1) mostrou que a EIPPM apresenta entre cinco e nove componentes.

Tabela 2 - Autovalores Empíricos e Aleatórios

\begin{tabular}{|c|c|c|c|}
\hline \multirow[b]{2}{*}{ Componente } & \multicolumn{2}{|c|}{ Autovalores iniciais } & \multirow[b]{2}{*}{$\begin{array}{l}\text { Autovalores } \\
\text { aleatórios }\end{array}$} \\
\hline & Total & $\begin{array}{c}\% \text { de } \\
\text { variância }\end{array}$ & \\
\hline 1 & 7.428 & 16.882 & 1.557874958 \\
\hline 2 & 2.845 & 6.465 & 1.499785611 \\
\hline 3 & 2.207 & 5.015 & 1.455350049 \\
\hline 4 & 1.809 & 4.111 & 1.417452029 \\
\hline 5 & 1.678 & 3.815 & 1.383688427 \\
\hline 6 & 1.511 & 3.434 & 1.351758646 \\
\hline 7 & 1.444 & 3.282 & 1.322373058 \\
\hline 8 & 1.297 & 2.948 & 1.294709761 \\
\hline 9 & 1.280 & 2.908 & 1.268207829 \\
\hline 10 & 1.167 & 2.653 & 1.243389176 \\
\hline$\cdots$ & $\ldots$ & $\ldots$ & $\ldots$ \\
\hline 44 & .252 & .572 & .557332992 \\
\hline
\end{tabular}

Fonte. Elaborado pelos autores, a partir dos dados da pesquisa. 
Figura 1 - Scree plot.

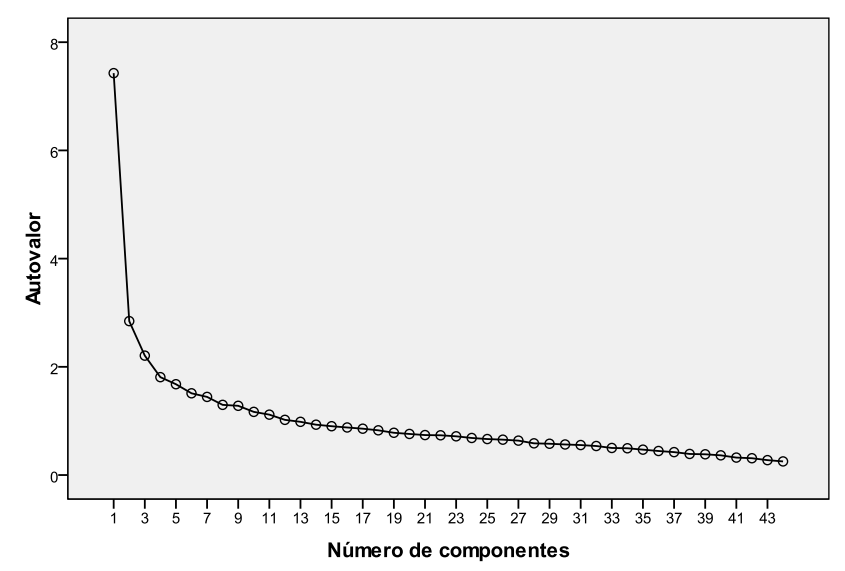

Fonte. Elaborado pelos autores, a partir dos dados da pesquisa.

De posse dessas informações, procedeu-se a uma análise fatorial PAF para a extração de nove e de cinco fatores com o objetivo de analisar a covariância residual de ambas as extrações. Com a extração de nove fatores, a covariância residual foi de $6 \%$, enquanto que essa covariância, no caso de cinco fatores, foi de $17 \%$. Obviamente, a complexificação fatorial de quase 50\% (passagem de 5 para 9 fatores) não justifica o ganho de apenas $9 \%$ de explicação da covariância residual. Mesmo assim, dois fatores da extração de cinco fatores se mostraram correlacionados (correlação entre Fator 1 e Fator 5 foi de 0,32). Foi, assim, tentada uma extração de quatro fatores, que deixou de explicar $22 \%$ da covariância residual, ou seja, $5 \%$ a menos do que a extração de cinco fatores. Ademais, na extração de quatro fatores, o Fator 4 obteve somente dois itens com carga boa, enquanto que a extração de cinco fatores aumentou os itens para quatro. Assim, foi decidido manter a extração de cinco fatores, cujos resultados e as discussões são, a seguir, apresentados.

O primeiro destes resultados, descrito na Tabela 3 mostra que a discriminação dos itens dos cinco fatores da EIPPM, informada pela correlação item-fator, que é muito forte. Com relação à validade dos itens, expressa pela carga fatorial que define a covariância entre o item e o fator, pode-se afirma que ela é boa, pois a média das cargas fatoriais é geralmente superior a 0,40 , em todos os fatores.

Tabela 4 - Discriminação e validade dos itens da EIPPM

\begin{tabular}{|c|c|c|c|c|c|c|c|c|c|c|c|c|c|c|c|}
\hline & & Fator1 & & & Fator2 & & & Fator3 & & & Fatort & & & Fator5 & \\
\hline & Carga & $r_{i t}$ & Dif. & Carga & $r_{i t}$ & Dif. & Carga & $\mathrm{r}_{\mathrm{it}}$ & Dif. & Carga & $\mathrm{r}_{\mathrm{it}}$ & Dif. & Carga & $r_{i t}$ & Dif. \\
\hline & & & & .327 & 0.553 & 3.59 & & & & & & & & & \\
\hline & .440 & 0.519 & 3.05 & & & & & & & & & & & & \\
\hline
\end{tabular}




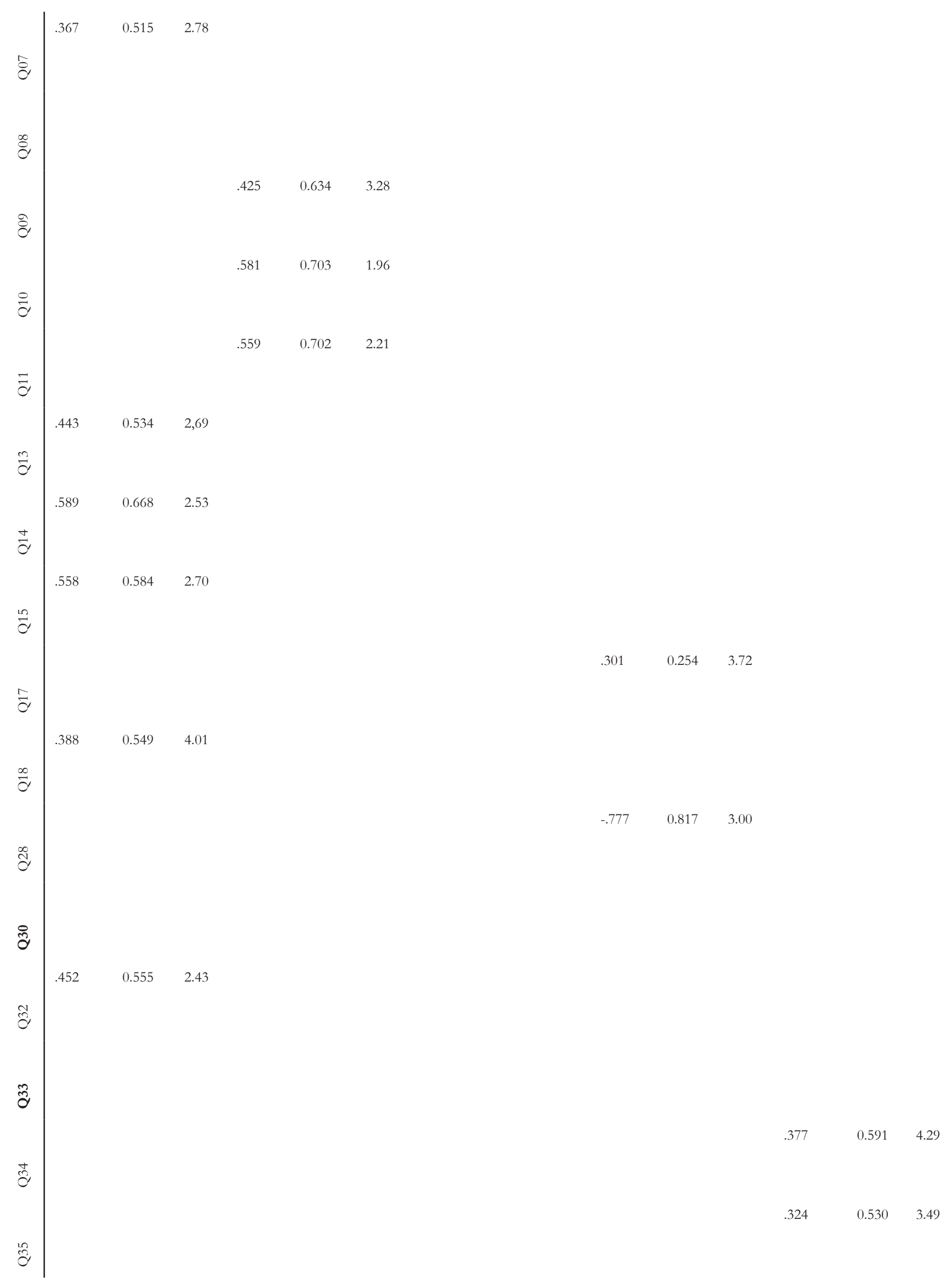




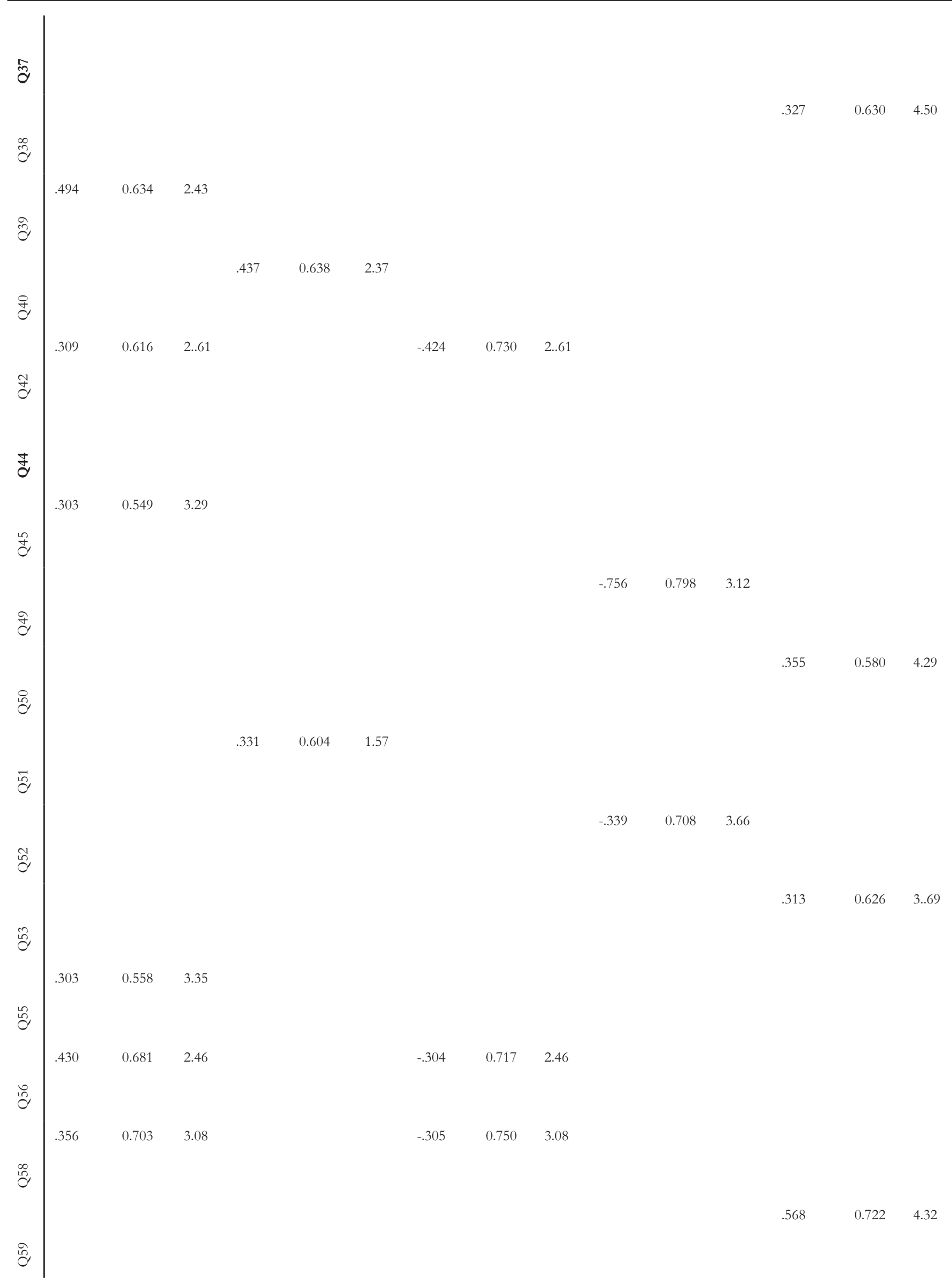




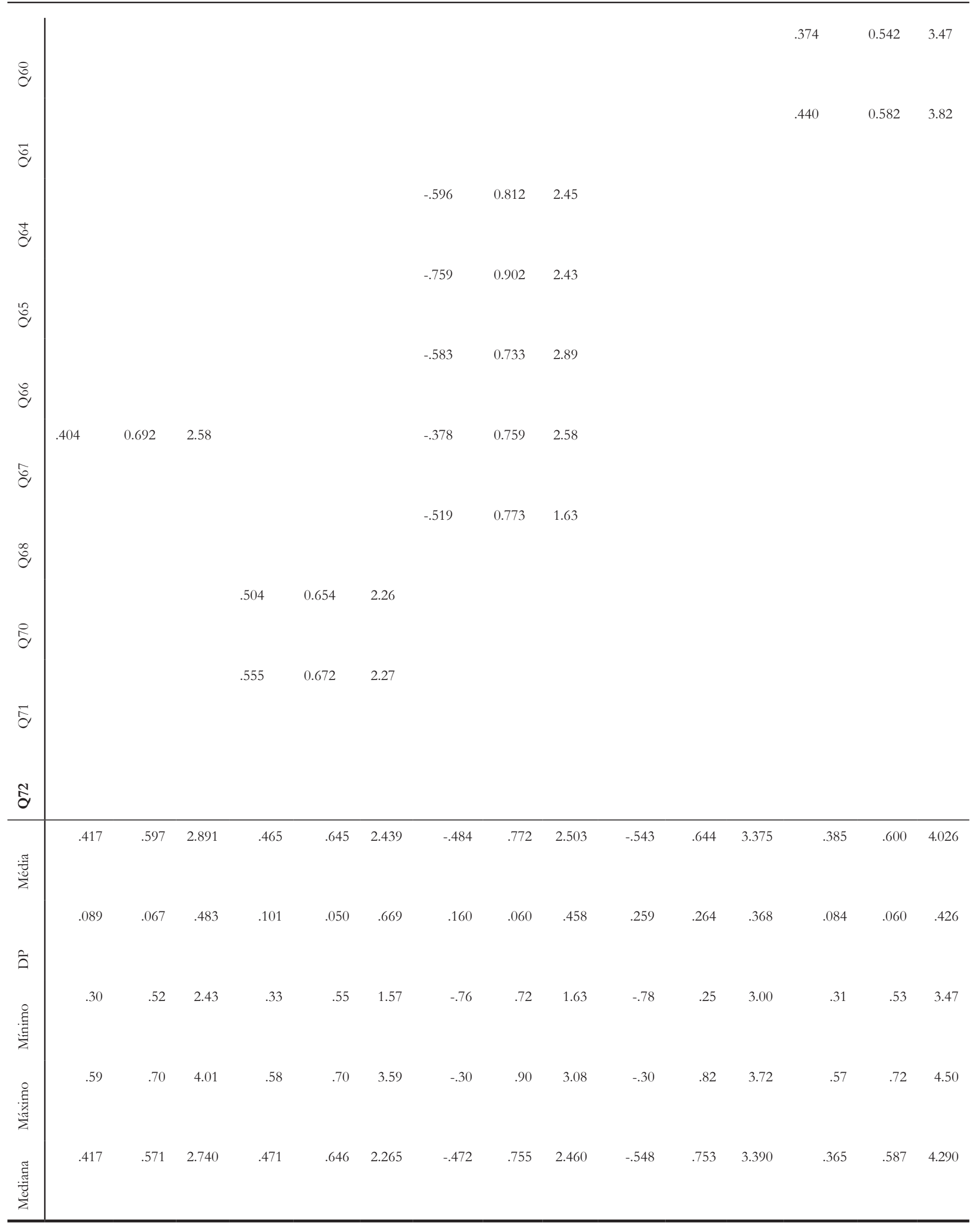

Fonte: Elaborado pelos autores, a partir dos dados da pesquisa.

Carga = carga fatorial; $r_{i t}=$ correlação polisserial item-fator; dif. $=$ dificuldade

Correlação entre $r_{i t}$ e carga fatorial: Fator 1, $r=0,571$; Fator 2, $r=0,947$; Fator 3, r = 0,803; Fator 4, r = 0,755; Fator 5, r = 0,653 
Com a análise da Tabela 4, verificam-se que 6 itens (Q08, Q30, Q33, Q37, Q44, Q72) não apresentaram cargas fatoriais inferiores ao limite de corte $>0,3$, (PASQUALI, 2009), portanto, foram excluídas.

Tabela 4 - Distribuição dos itens dos fatores da EIPPM por faixa de dificuldade

\begin{tabular}{|c|c|c|c|c|c|c|c|c|c|c|c|c|}
\hline \multirow[b]{2}{*}{$\begin{array}{l}\text { Faixa de } \\
\text { dificuldade }\end{array}$} & \multirow[b]{2}{*}{ faixa $^{a}$} & \multicolumn{2}{|c|}{ Fator 1} & \multicolumn{2}{|c|}{ Fator 2} & \multicolumn{2}{|c|}{ Fator 3} & \multicolumn{2}{|c|}{ Fator 4} & \multicolumn{3}{|c|}{ Fator 5} \\
\hline & & $\mathrm{f}$ & $\%$ & $\mathrm{f}$ & $\%$ & $\mathrm{f}$ & $\%$ & $\mathrm{f}$ & $\%$ & $\mathrm{f}$ & $\%$ & \\
\hline $\begin{array}{l}\text { Discordo } \\
\text { plenamente }\end{array}$ & $\begin{array}{l}1,00 \mathrm{a} \\
1,80\end{array}$ & 0 & 0,00 & 1 & 12,50 & 1 & 12,50 & 0 & 0,00 & 0 & & 0,00 \\
\hline $\begin{array}{l}\text { Descordo } \\
\text { pouco }\end{array}$ & $\begin{array}{l}1,80 \mathrm{a} \\
2,60\end{array}$ & 5 & 35,71 & 5 & 62,50 & 4 & 50,00 & 0 & 0,00 & 0 & & 0,00 \\
\hline Em dúvida & $\begin{array}{l}2,60 \mathrm{a} \\
3,40\end{array}$ & 8 & 57,14 & 1 & 12,50 & 3 & 37,50 & 2 & 50,00 & 0 & & 0,00 \\
\hline $\begin{array}{l}\text { Concordo } \\
\text { pouco }\end{array}$ & $\begin{array}{l}3,40 \mathrm{a} \\
4,20\end{array}$ & 1 & 7,15 & 1 & 12,50 & 0 & 0,00 & 2 & 50,00 & 4 & & 50,00 \\
\hline $\begin{array}{l}\text { Concordo } \\
\text { plenamente }\end{array}$ & $\begin{array}{l}4,20 \mathrm{a} \\
5,00\end{array}$ & 0 & 0,00 & 0 & 0,00 & 0 & 0,00 & 0 & 0,00 & 4 & & 50,00 \\
\hline
\end{tabular}

a: transformação da escala de 4 intervalos em 5 faixas

Fonte. Elaborado pelos autores, a partir dos dados da pesquisa.

O segundo resultados versa sobre à dificuldade dos itens, conforme descrito na Tabela 4 que:

Fator 1: excetuados os extremos, a distribuição é normal;

Fator 2: Há certa presença acentuado de itens difíceis e nenhum fácil;

Fator 3: os itens são todos difíceis ou medianos;

Fator 4: os itens são todos medianos ou fáceis;

Fator 5: todos os itens são fáceis.

Observa-se, assim, que no caso de fatores que cobrem conceitos socialmente aceitáveis, os itens se tornam fáceis (caso dos Fatores 4, e 5), porque os sujeitos têm tendência de concordar com eles, ocorrendo o contrário quando o fator cobre conceitos socialmente não desejáveis (caso dos Fatores 2 e 3). Por fim, são apresentados os resultados e discutidas as interpretações dos cinco fatores que compõem a EIPPM.

\section{Fator 1: Ambiente institucional e profissional favorável}

Observa-se na Tabela 5 que o Fator 1 reuniu itens que tratam do ambiente de trabalho, do salário, dos incentivos, do apoio de colegas e chefia. $\mathrm{O}$ fator, dessa forma, descreve o ambiente institucional e profissional favorável, com 13 itens e $\alpha=0,81(\mathrm{M}=2,85, \mathrm{DP}=0,79)$. Não foi verificada a melhoraria da parcimônia e a confiabilidade do fator com a retirada de qualquer dos itens, portanto, manteve-se os 13 itens originalmente retidos.

Tabela 5 - Interpretação do Fator 1.

\begin{tabular}{ll}
\hline Item & Fator 1 \\
\hline Q14 - Disponho de um ambiente saudável em meu trabalho. & 0,589 \\
Q15 - Em meu trabalho existe espaço para confraternização. & 0,558
\end{tabular}


Q39 - Minha instituição me oferece oportunidade de lazer.

Q32 - Meu salário é compatível com minhas atribuições.

Q13 - Disponho de bons equipamentos para a execução de minhas atividades.

Q5 - Acredito na divisão hierárquica de minha instituição.

Q56 - Sou recompensado quando presto um bom serviço.

Q67 - Tenho incentivos para me aperfeiçoar em meu trabalho.

Q18 - Estou satisfeito com minha profissão.

Q7 - As relações pessoais são valorizadas em minha organização.

Q58 - Sou valorizado em meu ambiente de trabalho.

Q42 - Participo de confraternizações com meus colegas de trabalho.

Q45 - Sou incentivado a trabalhar em equipe.

Este resultado revela a força do ambiente de trabalho, do salário, dos incentivos, do apoio de colegas e chefia do policial para a constituição de sua identidade. Fator este, responsável por esclarecer 11,01\% da variância do instrumento. A explicação de Sousa (2009) no que se refere à conformidade como valor importante para a polícia, ajuda a compreender esse Fator, pois reside no fato de que os policiais militares experimentam no exercício de sua atividade a necessidade haver consonância, no que se refere à obediência às regras e normas da organização. Já que a polícia apresenta como sustentáculos de sua estrutura os pilares da hierarquia e da disciplina, ou seja, a ênfase na obediência às regras de trabalho. Assim, seria possível inferir que, ao menos quando arguido a respeito do ambiente institucional e profissional, o policial faz sua avaliação com base em algum referencial ou contexto, que neste caso foram questões referentes ao dia-a-dia do serviço dentro da instituição. Nesse mesmo ponto, Tamayo (2005) esclarece que quando existe a preocupação da organização com a satisfação de seus membros, gera uma fonte rica de comprometimento organizacional. Dessa forma, a resposta aos itens do Fator 1 poderiam ser o resultados de uma operação cognitiva de avaliação em que a identidade profissional é comparada com esses referenciais, o que resulta em uma avaliação final de sua construção. Ou como aponta Pinto (2000) “a identidade preponderante será a profissional." (p.78).

\section{Fator 2: Relacionamento conflituoso no trabalho}

O Fator 2 fala de problemas no ambiente de trabalho, descrevendo, assim, um relacionamento conflituoso no trabalho, inicialmente com 8 itens e $\alpha=0,70$. Com a análise da confiabilidade, permitiu-se a retirada do item Q1, mantendo a mesma confiabilidade $(\alpha=0,70)$, , portanto com maior parcimônia. O segundo fator responde por 6,21\% da variância dos dados obtidos por meio do instrumento. Seus itens são apresentados na Tabela 6, a qual mostra que o fator reuniu itens referentes a aspectos de relacionamento social, relativos aos problemas no trabalho $(\mathrm{M}=2,44, \mathrm{DP}=0,80)$.

Tabela 6 - Interpretação do Fator 2

\begin{tabular}{ll}
\hline Item & Fator 2 \\
\hline Q10 - Costumo levar problemas de casa para o trabalho. & 0,581 \\
Q11 - Costumo levar problemas do trabalho para casa. & 0,559 \\
Q71 - Tenho problemas de relações interpessoais em meu trabalho. & 0,555 \\
Q70 - Tenho problemas com meus superiores hierárquicos. & 0,504
\end{tabular}


Q40 - Minha relação com os meus superiores é conflituosa.

Q9 - Convivo com o medo de punições disciplinares.

Q51 - Sinto vergonha em desempenhar minhas atividades na PMDF.

Q1 - A forma como sou tratado no trabalho influi na forma como trato a sociedade*.

* item excluído para aumentar a confiabilidade e a parcimônia.

O Fator reuniu itens referentes a aspectos de relacionamento social, relativos aos problemas no trabalho. Ainda para Pinto (2000) essa temática de relações conflituosas corrobora o que foi apresentado pelo Fator 2, pois é causada pelo trabalho do policial militar e pelas relações desenvolvidas nesse ambiente, que o obriga a agir sempre como policial militar, independente da situação, como se renunciassem a tudo aquilo que não fosse referente a vida profissional. Cabe relembrar que a identidade é construída em uma relação do eu com o outro, mas no caso do policial militar o outro é na maioria das vezes um policial, alguém que carrega o mesmo comportamento, pensamento e o mesmo referencial. O que acaba gerando, conforme Sousa (2001), uma quebra na cadeia de confiança que pressupõem as relações entre superiores, subordinados e pares. Isso dificulta a formação de uma identidade, pois existe a limitação das relações sociais, o que pode justificar o tratamento da polícia com a sociedade, haja vista o policial apresenta dificuldades em avaliar as transformações ocorridas na sociedade. O policial militar e levado, portanto, a atuar de acordo com os princípios da instituição, que toma como se seu fossem, o que pode gerar divergência do anseio social. Além de só conseguir se posicionar frente as mais diversas situações como um representante da instituição. O que explica os problemas surgidos da relação trabalho x família (costumo levar problemas de casa para o trabalho e costumo levar problemas do trabalho para casa), em que o policial é chamado para representar suas outras identidades (pai, marido, filho, etc.) e acaba atuando sempre como policial militar.

Pinto (2000, p. 80) a esse respeito faz o seguinte comentário:

Como as outras identidades foram mal construídas, mal estabelecidas, o policial militar pode até evitar de desempenhar os papéis relativos a elas, fazendo com que estas identidades fiquem mais empobrecidas ainda, fortalecendo, por consequência, a preponderância da sua identidade de policial militar. A socialização secundária do policial militar, por suas características particulares, limita o seu acesso a outros mundos sociais.

Com relação ao convívio com punições por desvios de conduta Sousa (2001) esclarece que é recorrente no discurso dos policiais militares a crítica à organização em virtude da injustiça das punições aplicadas, o que gera no policial, principalmente nos mais novos, o medo da sanção.

\section{Fator 3: Abertura no trabalho}

O Fator 3 diz respeito a liberdade de inovar, de questionar e de decidir. Assim, o fator cobre o conceito de abertura no trabalho, com 8 itens e $\alpha=0,85$. Não foi verificada a melhoraria da parcimônia e a confiabilidade do fator com a retirada de qualquer dos itens, portanto, manteve-se os 8 itens originalmente retidos. $(\mathrm{M}=2,52$, $\mathrm{DP}=0,97)$, observados na tabela 7 .

Tabela 7 - Interpretação do Fator 3

\begin{tabular}{lc}
\hline Item & Fator 3 \\
\hline Q56 - Sou recompensado quando presto um bom serviço. & $-0,304$ \\
Q67 - Tenho incentivos para me aperfeiçoar em meu trabalho. & $-0,378$
\end{tabular}


Q58 - Sou valorizado em meu ambiente de trabalho.

Q65 - Tenho espaço para inovar em meu trabalho.

Q64 - Tenho espaço para fazer questionamentos a meus superiores hierárquicos.

Q66 - Tenho espaço para tomar decisões em meu trabalho.

Q68 - Tenho liberdade de corrigir meus superiores hierárquicos.

Q42 - Minhas ideias são bem recebidas pelos meus chefes.

Esse resultado revela que a abertura no trabalho é responsável por esclarecer $7,74 \%$ da variância dos dados. Com relação a esse fator, verifica-se que a relação que Sousa (2009) chamou de sistema autônomo, em que existe uma relação positiva dos policiais militares com os valores autonomia. Apesar de ser uma organização militarizada há o espaço para propositura de formas inovadoras na atividade, as questões de valorização pessoal começam a ganhar importância nos contexto da polícia militar, bem como a abertura conseguida pelos estratos mais baixos da estrutura hierárquica militar. Isso pode ser confirmado, pela mesma autora, ao se tratar a atividade policial como portadora de uma série de especificidades, o que acarreta uma constante superação de limites, e necessidades de constantes adaptações.

Entretanto, como apontou Sousa (2001) existe a crença que as livres manifestações de opiniões dentro da organização, na maioria das vezes, se estiverem em contraposição ao pensamento dos superiores, pode vir a provocar reações desfavoráveis contra a pessoa que a emitiu. Tem-se que o poder hierárquico é mais valoroso do que o conhecimento e que a vontade do superior impera sobre a do subordinado.

\section{Fator 4: Vocação policial}

O Fator 4 versa sobre a escolha de ser policial e de estar satisfeito com a mesma. Assim, o fator cobre o conceito de vocação policial, inicialmente, com 4 itens e $\alpha=0,62$. Com a análise da confiabilidade, permitiuse a retirada do item Q17, que resultou em um acréscimo na confiabilidade $(\alpha=0,69)$, e maior parcimônia (M $=3,02, \mathrm{DP}=1,02)$. O quarto fator é responsável por explicar 5,67\% da variância dos dados. Seus itens são apresentados na Tabela 8, a qual mostra que o fator reuniu itens referentes à escolha de Ser Policial e de estar satisfeito com a mesma.

Tabela 8 - Interpretação do Fator 4

\begin{tabular}{lc}
\hline Item & Fator 4 \\
\hline Q28 - Ingressei na polícia por vocação. & $-0,777$ \\
Q49 - Sempre quis ser policial. & $-0,756$ \\
Q52 - Sinto-me realizado com minha profissão. & $-0,339$ \\
Q17 - Escolhi ser policial pela estabilidade do emprego*. & 0,301 \\
\hline
\end{tabular}

* item excluído para aumentar a confiabilidade e a parcimônia.

Para aprimorar o Fator, recomenda-se a revisão dos itens em virtude do valor do baixo alfa (mesmo que Hair et al., 2009 considerem o valor aceitável para pesquisas exploratórias), coma a inclusão de outras questões relacionadas ao ingresso na instituição, vocação, escolha profissional. Essa categoria não está diretamente relacionada aos aspectos da atividade policial ou mesmo ligada à organização, Diz respeito à formação da composição organizacional, onde os policiais militares ingressam por vocação ou pela estabilidade no emprego. Segundo Pinto (2000) são raros os trabalhos que permitem ao trabalhador seguir uma carreira, ou que 
possibilitem uma mobilidade ascendente. Ainda sobre o mesmo assunto o autor acrescenta que os extratos mais baixos da polícia são preenchidos com trabalhadores menos qualificados e as classes mais altas da hierarquia, os oficiais, são oriundos de uma classe social melhor aquinhoada, que puderam investir em educação e qualificação. Aqui cabe uma crítica ao estudo de Pinto (2000), no sentido da evolução das competências para se entrar na polícia militar, hoje os extratos da polícia são formados por pessoas bem qualificadas, já que o ingresso se dá pela contratação de pessoal de nível superior, que enfrenta um certame muito concorrido, além de vários outros exames, como psicológicos, de avaliação médica e física e de investigação social, que podem levar ao desligamento, do candidato a policial, pela reprovação em qualquer das fases do concurso. Todo esse processo é igual para o acesso ao oficialato ou para acesso como soldado. A diferença reside na formação profissional do policial, sendo o futuro oficial submetido a um curso superior de formação de oficiais, graduação em segurança pública, com duração de três anos, em regime integral, e o futuro soldado submetido a um curso de aproximadamente nove meses para sua formação como policial.

\section{Fator 5: Respeito profissional e social}

Como pode-se observar na Tabela 9 que o Fator 5 considera o relacionamento com os pares e com a sociedade, descrevendo o respeito do policial no ambiente de trabalho e na sociedade. Além de atingir os pressupostos da atividade policial. Assim, o fator cobre o conceito de respeito profissional e social do policial, com 8 itens e $\alpha=0,64(\mathrm{M}=3,99, \mathrm{DP}=0,59)$. Não foi verificada a melhoraria da parcimônia e a confiabilidade do fator com a retirada de qualquer dos itens, portanto, manteve-se os 8 itens originalmente retidos.

Tabela 9 - Interpretação do Fator 5

\begin{tabular}{lc}
\hline Item & Fator 5 \\
\hline Q59 - Tenho boas relações com meus pares. & 0,568 \\
Q61 - Tenho capacidade de mediação de conflitos. & 0,440 \\
Q34 - Meu trato com a sociedade é sempre cortês. & 0,377 \\
Q60 - Tenho bom preparo físico. & 0,374 \\
Q50 - Sigo normas padronizadas pela instituição. & 0,355 \\
Q38 - Minha imagem reflete a imagem da instituição policial. & 0,327 \\
Q53 - Meus colegas colaboram com o meu aperfeiçoamento profissional. & 0,324 \\
Q35 - Sinto-me respeitado em meu ambiente de trabalho. & 0,313 \\
\hline
\end{tabular}

O Fator 5 foi responsável por explicar $6,82 \%$ da variância total. O aprimoramento do Fator levaria em conta a revisão dos itens, novamente por conta do baixo valor do alfa, como a inclusão de outras questões relacionadas as relações sociais, respeito e trato social, além de questões referentes à atividade policial em si.

Os itens abordados nesse Fator nos mostram que os policiais militares atribuem importância aos relacionamentos intra e extra-corporação. Além de aliar algumas características importantes para o desempenho das atividades policiais, como o preparo físico, normas institucionais e conhecimentos específicos necessários, como por exemplo, o de resolução de conflitos. Com relação aos itens que retratam as relações com a comunidade, Pinto (2000) afirma que os policiais militares têm duas abordagens distintas, a primeira está vinculada a pessoas de classes sociais mais abastardas, em que o policial militar defere um trato mais cortês, já que existe, mesmo que simbolicamente, um sentimento de superioridade, de maior nível educacional, de conhecimento da lei. A segunda abordagem se manifesta quando da relação dos policiais militares com pessoas advindas de extratos mais baixos da sociedade, ocorrendo um inversão na percepção do outro, o policial passa a ser o sujeito que apresenta um destaque social, que detém o poder, o que pode fazer com ocorra a extrapolação dos limites, o que pode ocasionar violência policial. 
Tal passagem é confirmada através dos dizeres de Sousa (2001, p. 21):

(...) a profissão policial militar dá poder e que esse poder não é algo inerente ao indivíduo, mas está relacionado ao lugar que ocupa enquanto representante do estado. Percebe também que para exercê-lo deve ter responsabilidade e, principalmente, limites para que ele não seja usado de forma indiscriminada.

Como ocorreu na pesquisa de Sousa (2001), aqui também verificou-se um sentimento contraditório, em que alguns policiais se sentem honrados por fazer parte da instituição, enquanto outros se sentem desacreditados.

De maneira geral, a análise fatorial demonstrou que a EIPPM é composta por cinco fatores independentes, responsáveis por explicar $37,45 \%$ da variância total. Quando do delineamento da presente pesquisa não foi encontrado nenhum instrumento que permitisse avaliar a Identidade Profissional do Policial Militar. Neste sentido, concebeu-se esta escala, cuja variável correspondente vem sido considerada em pesquisas que tentam explicar como se estabelece o self. Esta escala se revelou multifatorial, agregando os itens em cinco fatores (ambiente institucional e profissional favorável, relacionamento conflituoso no trabalho, abertura no trabalho, vocação policial e respeito profissional e social). No que se refere à precisão, foi evidenciado um índice adequado, por intermédio da técnica alfa de Cronbach (PASQUALI, 2007; NUNALLY, 1978), apresentando um Alfa médio de 0,72 , o que pode ser considerado aceitável. Além desta técnica, a correlação interitens revelou boa consistência interna (CLARK; WATSON, 1995).

Neste ínterim, corrobora-se a adequação de empregar a medida descrita, que foi previamente validada, para se atestar, de forma específica na Polícia Militar, como anda o ambiente de trabalho dos Policiais, suas relações sociais, conflitos, como se dá a abertura no trabalho, a vocação do policial dessa unidade específica e seu comportamento frente à sociedade. Criou-se uma escala que pode ser empregada para diversos propósitos, não só pela PMDF, mas pelas outras instituições policiais brasileiras, que contam com uma ferramenta que ajuda compreender o Policial, seus anseios, problemas e relacionamentos. Uma vez comprovada à adequação dos cinco Fatores descritos, justifica-se considerá-los para compreender os antecedentes da formação da Identidade Profissional do Policial Militar do DF. Isso deve resultar na proposta de um modelo preditivo, considerando o poder explicativo de cada variável antecedente. Como não foi possível encontrar na literatura textos que abordassem a temática da identidade profissional em instituições policiais de forma mais aprofundada, buscou-se construtos correlatos, a esse respeito.

\section{Buscando Evidências de Predição: Análises e Discussões da Regressão}

Testes de relações predição foram realizados considerando as variáveis critério: ambiente profissional e institucional favorável (Fator 1); relacionamento conflituoso no trabalho (Fator 2); abertura no trabalho (Fator 3); vocação policial (Fator 4) e respeito profissional e social (Fator 5). As variáveis preditoras selecionadas foram aquelas que apresentaram correlações significativas com cada uma das variáveis dependentes.

$\mathrm{Na}$ primeira análise foi verificado o percentual da variação do Fator 1 (ambiente profissional e institucional favorável) explicado pelo tempo dividido, variável transformada, (até 18 anos na polícia e mais que 19 anos na polícia), pelos postos e graduações e pelo sexo.

Tabela 10 - Regressão Linear Múltipla Padrão para as Variáveis Preditoras dos Fatores 1

\begin{tabular}{llccc} 
Fator 1 & & & & \\
\hline Modelo & & B & Erro padrão & Beta \\
\hline 1 & (Constante) & 1,86 & 0,18 & \\
& sexo & 0,31 & 0,13 & $0,10^{*}$ \\
& postos e & 0,07 & 0,01 & $0,27^{* * *}$ \\
& graduação & & & \\
& tempo & 0,30 & 0,06 & $0,19 * * *$ \\
& dividido & & & \\
\hline
\end{tabular}

Nota: Modelo1: $\mathrm{R}^{2}=0,11 ; \mathrm{F}=25,37 ;{ }^{* * *}$ sig. 0,$00 ;{ }^{*} \mathrm{p}<0,05$;

$$
* * * \mathrm{p}<0,000
$$

Com relação à primeira análise, pode-se confirmar que tempo dividido (variável transformada que separa Policiais com até dezoito anos na Polícia daqueles que têm mais de 19 anos na Polícia), postos e graduações e sexo compuseram a equação de predição para o ambiente institucional e profissional favorável (Fator 1), com um peso razoável de explicação em uma relação direta com estas variáveis. Assim, para Rosa, Brito e Oliveira (2007), a socialização organizacional 
representada pelo processamento dos corpos ganha formas diferenciadas na organização militar. Aspectos da estrutura organizacional trazem uma forma de vigilância e controle total sobre o corpo dos indivíduos, na Polícia através da disciplina e da hierarquia. $\mathrm{O}$ que justifica os resultados encontrados e reafirma os ensinamentos presentes na TIS, já que a este respeito, Galinkin e Zauli (2011) escrevem que Henri Tajfel enxerga em relação ao ambiente físico e social, influencia na compreensão dos efeitos da natureza e a importância subjetiva do comportamento dos indivíduos em suas relações interpessoais.

A respeito da variável sexo, Rosa, Brito e Oliveira (2007) afirmam, que as mulheres devem passar um processo de aprendizagem, alinhando suas concepções de mundo (ethos) a uma cultura organizacional que preserva e reproduz a lógica da divisão hierárquica, a formalização, a disciplina e outros meios totalizantes de mediação de relações de trabalho. Assim, o que chamam de legado cultural se funde em valores masculinos socialmente construídos e historicamente reproduzidos, marcando a concepção do que é "ser policial militar", e a partir daí, passa a definir padrões de conduta moral, normas de comportamento e as formas de sentir, pensar e agir das mulheres. O que ajuda a entender porque os policiais, homens, com mais tempo de serviço e de postos e graduações superiores verificam o ambiente favorável.

$\mathrm{Na}$ segunda análise foi verificado o percentual da variação do Fator 2 (relacionamento conflituoso no trabalho) explicado pela idade, tempo dividido, variável transformada, (até 18 anos na polícia e mais que 19 anos na polícia) e pelo número de dependentes.

Tabela 11 - Regressão Linear Múltipla Padrão para as Variáveis Preditoras dos Fatores 2

\begin{tabular}{llccc}
\hline Fator 2 & & & & \\
\hline Modelo & & B & $\begin{array}{c}\text { Erro } \\
\text { padrão }\end{array}$ & Beta \\
\hline 1 & (Constante) & 3,667 & 0,184 & \\
& $\begin{array}{l}\text { número de } \\
\text { dependentes }\end{array}$ & 0,046 & 0,026 & $0,090^{*}$ \\
& Idade & $-0,043$ & 0,008 & $-0,389 * * *$ \\
& tempo & 0,178 & 0,099 & $0,111 *$ \\
& dividido & & & \\
\hline
\end{tabular}

Nota: Modelo1: $\mathrm{R}^{2}=0,07 ; \mathrm{F}=15,27 ; * * *$ sig. 0,$00 ;{ }^{*} \mathrm{p}<0,05$; $* * * \mathrm{p}<0,000$.
$\mathrm{Na}$ segunda análise foi verificado que compõem a equação de predição do Fator 2 (relacionamento conflituoso no trabalho), idade, tempo dividido, variável transformada, (até 18 anos na polícia e mais que 19 anos na polícia) e número de dependentes, com um peso razoável de explicação em uma relação inversa com idade e direta com as demais variáveis. A discussão dos conflitos experimentados pelos Policiais mais jovens, conforme apontam os resultados, podem encontrar respostas no estudo Rosa e Brito (2010), ao tratarem da socialização secundária, conceito que pode ser entendido pela necessidade de outros conhecimentos dos indivíduos por participarem de novos espaços de interação social, como o ingresso em uma organização Policial Militar, que envolvem a socialização de subculturas específicas, determinadas ora pela complexidade da divisão do trabalho, ora pela consequente distribuição social do conhecimento, dentro de uma sociedade específica. Sendo, portanto, uma fase posterior ao processo de socialização primária. Logo o jovem Policial, inserido em um novo contexto social, encontra problemas ao enfrentar a nova realidade em que se encontra, pois não abandonou as antigas concepções.

Ao se verificar a terceira análise foi obtido o percentual da variação do Fator 3 (abertura no trabalho) explicado pelos postos e graduações (de soldado a coronel), pela variável transformada, oficiais e praças (praças: do soldado ao subtenente e oficiais: do cadete ao coronel) e pela outra transformação soldados e o restante dos postos e graduações (soldado e do cabo ao coronel).

Tabela 12 - Regressão Linear Múltipla Padrão para as Variáveis Preditoras dos Fatores 3

\begin{tabular}{llccc}
\hline Fator 3 & & & & \\
\hline Modelo & & B & $\begin{array}{c}\text { Erro } \\
\text { padrão }\end{array}$ & Beta \\
\hline 1 & $\begin{array}{l}\text { (Constante) } \\
\text { Postos e } \\
\text { graduações }\end{array}$ & 2,06 & 0,17 & \\
& $\begin{array}{l}\text { soldados e } \\
\text { restante }\end{array}$ & $-0,04$ & 0,03 & $0,22^{*}$ \\
& $\begin{array}{l}\text { praça e } \\
\text { oficial }\end{array}$ & 0,20 & 0,17 & $-0,02$ \\
& & 0,12 & 0,10 \\
\hline
\end{tabular}

Nota: Modelo1: $\mathrm{R}^{2}=0,08 ; \mathrm{F}=16,99 ; * * *$ sig. 0,$00 ; * \mathrm{p}<0,05$.

$\mathrm{Na}$ terceira análise foi verificada a habilidade preditiva apenas para a variável postos e graduações. Essa 
variável explicou, individualmente, a variância da abertura no trabalho. Aqui novamente comparamse os resultados com as explicações de Rosa e Brito (2010) ao distinguirem a carreira de oficiais e praças, estando os primeiros inseridos em um processo de socialização mais intensa, pelo tempo decorrido em sua formação Policial, que duram três anos em regime integral e de semi-internato para o oficial, contra dez meses, em média para os praças. A maior abertura no trabalho, reconhecida pelos oficiais e pelos praças mais graduados, pode ser explicada pela natureza das funções exercidas pelo oficial, normalmente voltadas ao planejamento, à coordenação e ao controle de atividades desenvolvidas por subordinados. Quando se referem aos praças graduados, no caso dos sargentos, os autores apontam um equilíbrio entre atividades intelectuais e práticas, pois, a natureza das atividades desse segmento, pressupõe controle de subordinados e execução de algumas atividades. No nível mais elementar da hierarquia, os dos soldados predominam aspectos práticos, que os tornam elementos de execução das atividades militares.

$\mathrm{Na}$ quarta análise foi obtido o percentual da variação do Fator 4 (vocação policial) explicado pelos postos e graduações (de soldado a coronel), pelo número de dependentes, tempo no posto ou na graduação e tempo desde o último curso em anos.

Tabela 13 - Regressão Linear Múltipla Padrão para as Variáveis Preditoras dos Fatores 4

\begin{tabular}{llccc}
\hline Fator 4 & & & & \\
\hline Modelo & & B & $\begin{array}{c}\text { Erro } \\
\text { padrão }\end{array}$ & Beta \\
\hline 1 & $\begin{array}{l}\text { (Constante) } \\
\text { Graduação }\end{array}$ & 2,20 & 0,15 & \\
& 0,06 & 0,02 & $0,18^{* *}$ \\
& $\begin{array}{l}\text { número de } \\
\text { dependentes }\end{array}$ & 0,14 & 0,03 & $0,22^{* *}$ \\
& $\begin{array}{l}\text { tempo no } \\
\text { posto ou } \\
\text { graduação } \\
\text { tempo desde } \\
\text { o último } \\
\text { curso em } \\
\text { anos }\end{array}$ & 0,03 & 0,01 & $0,17^{* *}$ \\
& & & & \\
& & & & \\
\hline
\end{tabular}

Nota: Modelo1: $\mathrm{R}^{2}=0,07 ; \mathrm{F}=10,25 ; * * *$ sig. 0,$00 ; * \mathrm{p}<0,05$; $* * * \mathrm{p}<0,000$.

$\mathrm{Na}$ quarta análise as quatro variáveis independentes, postos e graduações (de soldado a coronel), número de dependentes, tempo no posto ou na graduação e tempo desde o último curso em anos, são preditoras significativas do Fator 4 (vocação policial). Todas as variáveis guardam uma relação direta, exceção feita ao tempo desde o último curso em anos, que apresenta uma relação inversa com a vocação policial.

Segundo Menandro e Souza (1996) os motivos básicos afirmados por Policiais Militares para o ingresso na carreira são: $48 \%$ pelo apreço pelo militarismo e/ ou vocação; $43 \%$ tinham familiares na corporação e $26 \%$ por problemas ligados ao desemprego. Já Cavassani (1998), em sua pesquisa junto a Policiais Civis, identificou outros fatores como um índice maior de importância, que motivaram o ingresso na Corporação Policial, passando pela importância e utilidade social da profissão, seguindo pela ideia de autoridade apresentada pela profissão, a necessidade de emprego também aparece como causa, seguido das vantagens de se seguir uma carreira policial.

$\mathrm{Na}$ última análise foi alcançado o percentual da variação do Fator 5 (respeito profissional e social) explicado pelo tempo na polícia militar e pela idade.

Tabela 14 - Regressão Linear Múltipla Padrão para as Variáveis Preditoras dos Fatores 5

\begin{tabular}{|c|c|c|c|c|}
\hline Modelo & & B & $\begin{array}{c}\text { Erro } \\
\text { padrão }\end{array}$ & Beta \\
\hline \multirow[t]{3}{*}{1} & (Constante) & 4,39 & 0,22 & \\
\hline & $\begin{array}{l}\text { tempo na } \\
\text { PM }\end{array}$ & 0,03 & 0,01 & $0,37^{*}$ \\
\hline & idade & $-0,02$ & 0,01 & $-0,28^{*}$ \\
\hline
\end{tabular}

Nota: Modelo1: $\mathrm{R}^{2}=0,02 ; \mathrm{F}=6,60 ;{ }^{* *}$ sig. 0,$01 ;{ }^{*} \mathrm{p}<0,05$.

$\mathrm{Na}$ última análise, tempo na Polícia Militar e idade se mostraram preditoras significativas do Fator 5, a primeira variável guardou uma relação direta com o fator e a segunda uma relação inversa. Ou seja, o respeito profissional e social é percebido pelos Policiais com mais tempo de Polícia, o contrário quando a variável que se coloca é a idade, assim, Policiais mais jovens percebem, em menor grau, o respeito profissional e social.

Sobre esse assunto, Brito e Souza (2004) comentam que é imprescindível, para as intervenções que buscam a otimização e a democratização do trabalho policial, a consideração de suas representações sociais sobre 
sua própria condição profissional, não se deixando esquecer, da relação entre a sociedade, a instituição policial e o Estado. Neste sentido, apresenta-se necessário considerar as diversas injunções que criam barreiras na execução de suas funções profissionais num universo ambíguo, em que se fala na lei, mas não se pode cumpri-la em virtude das condições de infraestrutura, das deficiências na profissionalização, da solicitude de ações extrajudiciais e do recurso à violência ilegítima.

\section{Conclusão}

Foram verificadas evidências favoráveis de validade de construto e precisão para a escala de identidade profissional policial militar. Foi encontrada uma estrutura multifatorial e razoável consistência interna. Os resultados indicaram que a Identidade Profissional do Policial é um construto paralelo ao da Identidade Social. Verificou-se, ademais, pelas análises, que ocorre uma preponderância da identidade profissional. De posse desses dados, cada Organização Policial estará abastecida de informações suficientes e necessárias para implementar soluções ou programas que busquem o aperfeiçoamento do profissional Policial Militar.

Novas evidências de validade e precisão devem ser estimuladas, buscando-se, por exemplo, conhecer a estabilidade temporal por meio de teste re-teste, ou ainda a validade nomológica desta medida, considerando a interação com a Polícia. Salienta-se a lacuna na literatura sobre a identidade de policiais, sobretudo no cenário nacional, constituíndo-se em importante agenda para pesquisas futuras. Com relação às análises realizadas na presente pesquisa, elas se mostraram pertinentes, mas isso não significa que outras análises estatísticas mais robustas possam ser utilizadas.

Como perspectivas para futuros estudos, e corrigindo as falhas apontadas nas limitações do estudo, sugerese que os dados sejam submetidos a análises adicionais (e.g., equações estruturais) a fim testar o modelo exploratório sugerido neste estudo. Especificamente, recomenda-se que a relação entre os Fatores da identidade profissional e outras medidas multi-item de identidade seja investigada, a fim de verificar se os resultados devem ser interpretados como um construto independente ou se trata-se simplesmente de um conjunto de variáveis que formam uma dimensão do construto da identidade, conforme já mencionado. Os fatores relacionamento conflituoso no trabalho, vocação policial e respeito profissional e social precisam ser aprimorados e merecem atenção especial em futuros estudos. Outra sugestão é a realização das mesmas análises fatoriais exploratórias utilizando metades diferentes e aleatoriamente divididas da amostra obtida neste estudo, a fim de se verificar a estabilidade dos resultados observados na validação dos instrumentos.

Sugere-se, ainda, conforme já mencionado, a realização de estudos experimentais a fim de compreender melhor o processo de construção e transformação da identidade. Não menos necessária é a comparação dos efeitos da apresentação da ordem das perguntas no instrumento de pesquisa, dos efeitos de diferentes procedimentos de aplicação (e.g., aplicação via internet e aplicação presencial).

Recomenda-se, por fim, que novos estudos sejam realizados com amostras (e.g., amostras de policiais de todos os níveis hierárquicos) e procedimentos diferentes de aplicação (e.g., aplicação via internet) a fim comparar os resultados. A realização de estudos em outros contextos, polícias civis, federal e militares de outros Estados, são úteis para que se verifique até que ponto a adoção de um modelo geral de identidade profissional é aplicável a outras polícias.

\section{Referências}

ALBERT S.; ASHFORTH B. E.; DUTTON J. E. Introduction to special topic forum. Organizational identity and identification: charting new waters and building new bridges. Academy of Management Review, v. 25, pp.13-17, 2000.

ALBERT, S.; WHET'TEN, D. “Organizational identity", in CUMMINGS, L.L. and STAW, B.M.(Eds), Research in Organizational Behavior, v. 7, JAI Press, Greenwich, CT, 1985.

\section{AMÂNCIO, L. Identidade social e relações intergrupais. In: J. VALA E M. B. MONTEIRO (Orgs.). Psicologia Social, Lisboa, Fundação Calouste Gulbenkian, 1993.}

ASHFORTH B. E.; MAEL F. A. Scoial identity theory and the organisation. Academy of Management Review, v.14, pp. 20-39, 1989.

BAUGNET, L. L'identité sociale. Dunod: Paris,1998.

\section{BAYLEY, D. H. Padrões de Policiamento:}


Uma Análise Internacional Comparativa. (BELMONTE, R. A., Trad.). São Paulo: EDUSP, 2006.

BRANDÃO, C. R. Identidade e etnia - a construção da pessoa e resistência cultural. São Paulo: Brasiliense, 1986.

BREWER, M. B. The role of ethnocentrism in intergroup conflict. In: AUSTIN, W. G.; WORCHEL, S. (Eds.). The Social Psychology of Intergroup Relations. Monterey, California: Brooks/Cole, 1979.

BREWER, M. B. On the social origins of human nature. In C. MCGARTY \& S. A. HASLAM (Eds.), The message of social psychology. (pp. 54-62). Oxford, UK: Blackwell, 1997.

BRITO, A. S.; SOUZA, L. (2004). Representações sociais de policiais civis sobre profissionalização. Sociologias (UFRGS), Porto Alegre. v. 6, n. 12, p. 304327, 2004.

CAPPELLE, M. C. A. O trabalho feminino no policiamento operacional: Subjetividade, Relações de Poder e Gênero na Oitava Região da Polícia Militar de Minas Gerais. Tese de Doutorado não publicada. Departamento de Ciências Administrativas, Universidade Federal de Minas Gerais, 2006.

\section{CAVASSANI, S. M. C. A. Utilização de Violência} na Atividade Policial: Da Insanidade Coletiva à Loucura Solitária. (Dissertação de Mestrado em Psicologia). Universidade Federal do Espírito Santo, Espirito Santo, 1998.

CERULO, K. A. Identity Construction: New Issues, New Directions, Annual Review of Sociology. v. 23 n. 1, pp. 385-409, 1997.

CHENEY G. Rhetoric in an organizational society, managing multiple identities. Columbia, SC: University of South Carolina Press, 1991.

CLARK, A. C., \& WATSON, D. Constructing validity: basic issues in objective scale development.

Psychological Assessment, v. 7, pp. 309-319, 1995.

COOLEY, C. H. Nature and the Social Order. New York: Charles Scribner's Sons, 1902.

COOLEY, C. H. Social Organization: a Study of the Larger Mind, New York: Charles Scribner's Sons, 1922.

CORLEY, K.G.; HARQUAIL, C.V.; PRAT'T, M.G.; GLYNN, M.A.; FIOL, C.M.; \& HATCH,
M.J. Guiding organizational identity through aged adolescence. Journal of Management Inquiry, v.15, n.2, p.85-99.

CUNHA, N. V. Como se fabrica um policial: considerações em torno dos processos de socialização e formação profissional. Comum. Rio de Janeiro, v. 9, n. 22, p. 198-207, 2004.

DUBAR, C. Identités collectives et individuelles dans le champ professionnel. In M. COSTER, F. PICHAULT (Orgs.). Traité de sociologie du travail. Bruxelles: De Boeck-Wesmael, 1994.

DUBAR, C. A Socialização: Construção de identidades sociais e profissionais. (Silva, A. S. M., Trad.). São Paulo: Martins Fontes, 2005.

ELLEMERS, N.; SPEARS, R.; DOOSJE, B. (2002). Self and social identity. Annual Review of Psychology, 53, 161-186, 2002.

FAIAD, C.; DELABRIDA, Z. N. C.;

NASCIMENTO, T. G. Survey Sobre a Qualidade do Serviço de Segurança Oferecido pela Polícia Militar Segundo Proprietários e Funcionários de Comércio em Brasília. Psicologia em Pesquisa (UFJF), 5, 77 85, 2011.

FIELD, A. Descobrindo a estatística usando o SPSS. (L. Viali, Trad.). Porto Alegre: Artmed, 2009.

GALINKIN, A. L.; ZALUI, A. Identidade social e alteridade. In: TORRES, C. V.; NEIVA, E. R. (Orgs.) Psicologia Social: Principais temas e vertentes. Porto alegre: Artmed, 2011.

GILL, R. Análise de discurso. Em M. W. BAUER; GASKELL, G (Ed.). Pesquisa qualitativa com texto, imagem e som. Um manual prático. (P. A. Guareschi, Trad.). (pp. 244 - 270). Petrópolis, RJ: Vozes, 2007.

GOFFMAN, E. The Presentation of Self in Everyday Life. London: Penguin Books, 1959[2011].

HAIR, J. F., BLACK. W. C., ANDERSON, R. E., \& TATHAM, R. L. Análise multivariada de dados. (A. S. Sant'Anna, Trad.). Porto Alegre: Bookman, 2009.

HALL, S. A identidade cultural na pósmodernidade. (T. T. Silva \& G. L. Louro, Trad.). Rio de Janeiro: DP\&A, 2000.

HUMPHREYS M.; BROWN A. D. Narratives of 
organizational identity and identification: A case study of hegemony and resistance. Organization Studies, v. 23, pp. 421-447, 2002.

LEDESMA, R.; IBAÑEZ, G. M.; MORA, P. V. Análisis de consistência interna mediante Alfa de Cronbach: un programa basado en gráficos dinâmicos. Psico-USF, v.7, n. 2, pp. 143-152, 2002.

MACHADO, H. V. A identidade e o Contexto Organizacional: Perspectivas de Análise. RAC. Revista de Administração Contemporânea. Curitiba. v. 7, n. Especial, p. 51-73, 2003.

MAINGUENEAU, D. Gênese dos Discursos. (S. Possenti, Trad.). Curitiba: Criar Edições, 2005.

MEAD, G. H. Social Psychology as Counterpart to Psichological Psychology. The Psychological Bulletin, 1, p. 401-408, 1909.

MEAD, G. H. What Social Objects Must Psychology Presuppose? In: Reck, A. J. (Org.). Selected Writings of George Hebert Mead. Chicago: University of Chicago Press, 1910.

MEAD, G. H. Mind, Self and Society: from the standpoint of a social behaviorist. Chicago: University of Chicago Press, 1934.

MENANDRO, P. R. M.; SOUZA, L. O cidadão policial militar e sua visão da relação políciasociedade. Psicologia USP. São Paulo. v. 7, n. 1/2, pp. 133-141, 1996.

MUNIZ, J. Ser policial é sobretudo uma razão de ser: cultura e cotidiano da Polícia Militar do Estado do Rio de Janeiro. Tese de Doutorado. IUPERJ, 1999.

MYERS, David. G. (2014). Psicologia Social. McGraw-Hill: Porto Alegre.

NASCIMENTO, T. G.; TORRES, C. V.; PIMENTEL, C. E. Evidências de Validade e Precisão da Escala de Atitudes Frente à Polícia.

Revista Brasileira de Segurança Pública, v.9, pp. 42-56, 2011.

NUNNALLY, J. C. Psychometric theory. New York: McGraw-Hill, 1978.

PASQUALI, L. Validade dos testes psicológicos: será possível reencontrar o caminho? Psicologia: Teoria e Pesquisa, v.23, n. spe, pp. 99-107, 2007.

PASQUALI, L. Análise Fatorial para Pesquisadores. Brasília: LabPAM, 2009.
PASQUALI, L. Testes referentes a construto: teoria e modelo de construção. In PASQUALI L. \& Cols. Instrumentação psicológica: fundamentos e práticas. Porto Alegre: Artmed, 2010.

PINTO, R. J. V. M. Trabalho e Identidade: $O e n$ faço construindo o eu sou. Dissertação de Mestrado não publicada. Instituto de Psicologia, Universidade de Brasília, 2000.

POT'TER, J.; Wetherell, M. Discourse and SocialPsychology: Beyond Attitudes and Behaviour. London: Sage Publications, 1987.

RAVASI D., P. N. Strategies of alignment: Organizational identity management and strategic change at Bang \& Olufsen. Strategic Organization, v. 9, pp. 103-135, 2011.

RIANTOPUTRA C. D. Know thyself: Examining factors that influence the activation of organizational identity concepts in top managers' minds. Group \& Organization Management, v. 35, pp. 8-38, 2010.

ROSA, A.; BRITO, M. J.; OLIVEIRA, F. M. Os Sentidos da Violência nas Organizações: Uma Análise Construcionista da História de Vida de uma Policial Militar. Gestão e Sociedade. v. 1, pp. 1-31, 2007.

ROSA, A. \& BRITO, M. J. "Corpo e Alma nas Organizações: um Estudo Sobre Dominação e Construção Social dos Corpos na Organização Militar. Revista de Administração

Contemporânea. v. 14, n. 2, pp. 194-211, 2010.

SAINSANLIEU, R. Identité au travail les effets culturels de l'organisation. Paris: Presses de la Fondation Nationale de Sciences Politiques, 1977.

SAINSANLIEU, R. L'identité au travail: une expérience partagée. In: Francfort, J. et al. Les mondes sociaux de l'entreprise. Paris: Sociologie Économique, 1995.

SCOTT, T.; LANE, L. A stakeholder approach to organizational identity. Academy of Management Review, v. 25, n. 1, pp. 43-62, 2000.

SOUSA, R. R. Os processos de construção da identidade no trabalho do policial militar na atividade de policiamento ostensivo em Belo Horizonte. Dissertação de Mestrado não publicada. Faculdade de Filosofia e Ciências Humanas, Universidade Federal de Minas Gerais, 2001.

SOUSA, R. R. Análise do perfil cultural das organizações policiais e a integração da gestão 
em segurança pública em Belo Horizonte. Tese de Doutorado não publicada. Instituto de Psicologia, Universidade de Brasília, 2009.

SOUZA, L. Processos de identidade social: da intolerância e violência à utopia solidária. Simpósio Nacional de Psicologia Social e do Desenvolvimento. Violência e Desenvolvimento Humano: textos completos. Vitória: Programa de Pós-Graduação em Psicologia/PROCAD-CAPES. Vol. 1. pp. 131-138, 2005.

STETS, J. E., \& BURKE, P. J. Identity theory and social identity theory. Social Psychology Quarterly, v. 63, n. 3, 224-237, 2000.

TABACHNICK, B. G.; FIDELL L. S. Principal Components and Factor Analisys. In. Using Multivariate Statistics (4 ed., pp. 582-652). Needdham Heights, MA: ALLYN \& BACON, 2000.

TAJFEL, H. Grupos Humanos e Categorias Sociais: estudos em psicologia social. (L. Amâncio, Trad.). Vol. I, Lisboa, Livros Horizonte, 1982.

TAJFEL, H. Grupos Humanos e Categorias Social: estudos em psicologia social. (L. Amâncio, Trad.). Vol. II, Lisboa: Livros Horizonte, 1983.

TAJFEL, H.; TURNER, J. C. (1979). An integrative theory of intergroup conflict. Em: W. G. AUSTIN E S. WORCHEL (Org.). The Social Psychology of Intergroup Relations, Monterey, Brooks, 1979.

TAMAYO, A. Valores organizacionais: sua relação com a satisfação no trabalho, cidadania organizacional e comprometimento afetivo. Revista de Administração Mackenzie, v. 6, n. 3, pp. 192213, 2005.

WHETTEN, A. D.; GODFREY, P. C. Identity in organizations: Building Theory Through Conversations. London: Sage Publications, 1998. 